\title{
Assessment of Efficacy of Different Teaching Methods of Tooth Brushing on Oral Hygiene Status in Adults
}

\author{
${ }^{1}$ Mohammed Asif, ${ }^{2}$ Shobha KS, ${ }^{3}$ Anirban Chatterjee
}

\begin{abstract}
Introduction: Tooth brushing plays a vital role in effective plaque control, which depends on the effectiveness of the particular method and the ease with which the procedure is carried out. Hence, the aim of this study was to assess the effect of different teaching methods of tooth brushing on oral hygiene status in adults.
\end{abstract}

Materials and methods: Eighty subjects were divided into four groups, each with 20 and assigned to different training methods. Twenty subjects were in control group and the rest in the experimental group. Each experimental group was further subdivided into two groups, namely reinforcers and nonreinforcers, with 10 subjects in each group. The plaque scores of these subjects were measured before and 1 week after the training sessions. The data analysis was carried out using the Statistical Package for the Social Sciences (SPSS) 20.0 and two-way analysis of variance (ANOVA).

Results: There was significant reduction in the plaque scores due to different training methods $(f=12.218, p<0.05$ ). Maximum reduction was seen in the instruction on cast method. There was significant difference in the plaque scores in the reinforcers and nonreinforcers $(f=4.897, p<0.05)$. A small survey conducted among participants revealed that individual as a model was an easy method to learn brushing.

Conclusion: The instruction on cast method was effective in reducing the plaque scores compared with the other methods.

Keywords: Adults, Plaque scores, Teaching, Tooth brushing.

How to cite this article: Asif M, Shobha KS, Chatterjee A. Assessment of Efficacy of Different Teaching Methods of Tooth Brushing on Oral Hygiene Status in Adults. J Health Sci Res 2017;8(1):25-30.

\section{Source of support: Nil}

Conflict of interest: None

\section{INTRODUCTION}

Dental plaque is considered as the possible causative agent of major dental diseases, such as dental caries and periodontal disease. ${ }^{1}$ The microorganisms harbor themselves onto the tooth structure in the form of biofilm, thus leading to formation of the dental plaque. World

\footnotetext{
${ }^{1}$ Postgraduate Student, ${ }^{2}$ Reader, ${ }^{3} \mathrm{Head}$

${ }^{1-3}$ Department of Periodontics, The Oxford Dental College Bengaluru, Karnataka, India
}

Corresponding Author: Mohammed Asif, Postgraduate Student, Department of Periodontics, The Oxford Dental College, Bengaluru, Karnataka, India, Phone: +91-8030219701 e-mail: mohdasif2311@gmail.com
Health Organization (WHO) defined dental plaque as a specific but highly variable structural entity, resulting from sequential colonization of microorganisms on tooth surfaces, restorations, and other parts of the oral cavity, composed of salivary components like mucin, desquamated epithelial cells, debris, and microorganisms, all embedded in extracellular gelatinous matrix. ${ }^{2}$

In 1965, Loe and et al demonstrated that subjects with healthy gingiva developed clinical signs of gingivitis within two to three weeks of refraining from all oral hygiene practices due to undisturbed accumulation of dental plaque. On resumption of adequate oral hygiene, the gingival tissue inflammation subsided within a week. ${ }^{3}$

Studies by Lindhe et $\mathrm{al}^{4}$ and Smulow et $\mathrm{al}^{5}$ demonstrated that mechanical removal of supragingival plaque affects the nutrition of subgingival organisms to affect the micro flora composition in shallow $(4 \mathrm{~mm})$ and moderate pockets $(6 \mathrm{~mm})$. The attraction of microbes to pellicle begins at the delicate gingival margin, particularly on proximal surfaces. All these studies provide the evidence that removal of microbial plaque leads to cessation of gingival inflammation, and cessation of plaque control measure leads to recurrence of inflammation. The removal of plaque also decreased the rate of formation of calculus. Thus eliminating the plaque and calculus is the key to prevent the occurrence of periodontal disease or halting the progression of the disease. Hence, dental plaque being the primary etiological factor in progression of gingivitis and periodontitis, prevention, elimination, and control of dental plaque formation are the important steps in the prevention of gingivitis as well as minimizing the severity of periodontal disease.

The daily disruption of dental plaque, at and above the gingival margin, appears to be critical in countering the potential of the plaque to cause gingival inflammation. Patient needs to maintain plaque at levels compatible with health in order to prevent the breakdown of microbial homeostasis. Individual skills and acquired behavior patterns determine how effective controls can be. ${ }^{6}$

Tooth brushing is considered a primary mechanical means of removing substantial amount of plaque in order to prevent oral disease, including gingivitis and dental caries, while also maintaining dental esthetics and preventing halitosis. Mechanical plaque removal with a manual tooth brush remains the primary method 
of maintaining a good oral hygiene for the majority of the population.

The effectiveness of the tooth brush, however, depends on any one individual acquiring the skills and having the personal motivation to use it properly. There is substantial evidence showing that tooth brushing and other mechanical cleansing procedures can reliably control plaque, provided that cleaning is sufficiently thorough and performed at appropriate intervals.

Although there are various studies done to test the efficacy of different teaching methods of tooth brushing in children, there has been no study done in adults. Hence, the aim of this study was to assess the effect of different teaching methods of tooth brushing on oral hygiene status in adults.

\section{MATERIALS AND METHODS}

\section{Source of Data}

A randomized clinical trial was carried out on subjects who were recruited from the Department of Periodontics, The Oxford Dental College, Bengaluru.

\section{Method of Collection of Data}

A total of 80 subjects were randomly selected for the study based on inclusion and exclusion criteria. Subjects were explained in detail about the study procedure, and informed written consent was obtained from the patient before including him or her in the study.

\section{Inclusion Criteria}

- Systemically healthy individuals

- Subjects with mild gingivitis.

\section{Exclusion Criteria}

- Advanced periodontal disease

- Treatment for periodontal disease within the last 12 months

- Pregnant or lactating mothers

- Smokers

- Individuals who have undergone scaling within the last 3 months.

A total of 80 subjects with mild gingivitis were divided into four groups based on training (group 1: Control group, and three experimental groups, namely group 2: Cast, group 3: Audio visual method and group 4: Individual as model). Each group consists of 20 subjects. These groups, other than the control groups, were further divided into two subgroups, namely reinforcer and nonreinforcer; each subgroup with 10 subjects. The modified bass brushing technique was demonstrated.

The group 1 (control group) received no instructions on the brushing technique, whereas in the experimental groups, group 2 (cast group), Modified Bass brushing technique was demonstrated on a study cast. In group 3 (audio visual group), a short video of Modified Bass brushing technique was played, and lastly in group 4 (individual as a model), each subject received instructions for Modified Bass brushing technique using individual as a model.

The plaque scores before the training session for all the four groups were measured. Then the subjects in the three experimental groups were trained in their respective methods for brushing. For the subjects in the reinforcement groups of the experimental groups, the training was repeated after three days. The plaque scores for all 80 subjects were measured after a period of 1 week. Plaque scores were measured using Turesky-GilmoreGlickman modification of Quigley-Hein plaque index. Plaque was assessed on the labial, buccal, and lingual surfaces of all the teeth after using a disclosing agent. The scores given were: 0: No plaque; 1 : Separate flecks of plaque at the cervical margin of the tooth; 2: A thin continuous band of plaque (up to $1 \mathrm{~mm}$ ) at the cervical margin; 3: A band of plaque wider than $1 \mathrm{~mm}$ but covering less than one-third of crown of the tooth; 4: Plaque covering at least one-third but less than two-thirds of the crown; 5: Plaque covering two-thirds or more of the crown. All the groups received a round of ultrasonic scaling after the initial plaque scores were assessed followed by instructions on the correct brushing technique for the experimental groups. The brushing technique taught was modified bass technique. A questionnaire was also asked to assess the attitude toward the tooth brushing instructions during the follow-up period, as follows:

- Do you think your brushing is effective?

- How many minutes do you brush now?

- Are you happy with the way you are brushing now?

- Was it easy to learn this technique of brushing?

- Has it helped you brush better?

\section{Statistical Analysis}

The data analysis was carried out using Statistical Package for the Social Sciences (SPSS) 20.0. Two-way analysis of variance (ANOVA) with repeated measure was administered to test the efficacy of the training methods, and reinforcement in reducing the plaque scores.

\section{RESULTS}

Table 1 gives the plaque scores of the subjects before and after training.

Table 1 reveals that there is a dip in the plaque scores for all the three training methods, but it is more for individual instruction on cast. Also, it can be seen that the percentage dip is minimum for the control group. 
Table 1: Plaque scores before and after different training methods

\begin{tabular}{llll}
\hline \multirow{2}{*}{ Methods of training } & \multicolumn{2}{c}{$\begin{array}{c}\text { Plaque score } \\
\text { mean (SD) }\end{array}$} & $\begin{array}{l}\text { Percentage of } \\
\text { decrease in the } \\
\text { plaque scores }\end{array}$ \\
\cline { 2 - 4 } & Baseline & After training & pla \\
Control group & 0.865 & 0.801 & 7.40 \\
Individual instruction & $(0.219)$ & $(0.197)$ & \\
on cast & 0.710 & 0.546 & 23.099 \\
Audiovisual & $(0.217)$ & $(0.237)$ & \\
& 0.779 & 0.681 & 12.580 \\
Individual as model & $(0.185)$ & $(0.164)$ & \\
& 0.938 & 0.841 & 10.34 \\
& $(0.147)$ & $(0.142)$ & \\
\hline
\end{tabular}

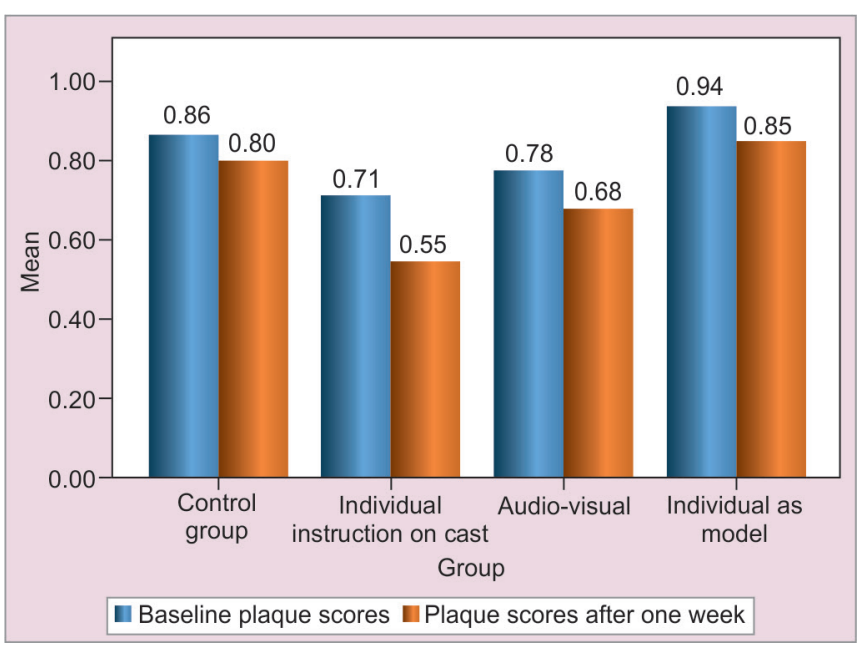

Graph 1: Average plaque scores

Graph 1 shows the multiple bar chart depicting the averages of plaque scores before and after training for various training methods.

Table 2 shows that the percentage of dip for nonreinforcers is more compared with that of reinforcers.

Graph 2 shows the multiple bar chart depicting the averages of plaque scores before and after training for the two groups.

The hypotheses tested in this study are:

- $\mathrm{H}_{0 \mathrm{~T}}$ : There was no significant difference in the plaque score due to different methods of training.

- $\mathrm{H}_{0 \mathrm{G}}$ : There was no significant difference in the plaque scores between the two groups, i.e., reinforcers and nonreinforcers groups.

- $\mathrm{H}_{0 \mathrm{P}}$ : There was no significant difference in the plaque scores between pre- and posttraining sessions.

- $\mathrm{H}_{0 т \mathrm{TP}}$ : There was no significant interaction effect of the training methods and pre- and posttraining sessions on the plaque scores.

- $\mathrm{H}_{0 \mathrm{GP}}$ : There was no significant interaction effect of groups and pre- and posttraining sessions on the plaque scores.

- $\mathrm{H}_{0 \mathrm{TG}}$ : There was no significant interaction effect of groups and training methods on the plaque scores.
Table 2: Comparison of plaque scores between reinforcers and nonreinforcers at baseline and after training (including control group)

\begin{tabular}{|c|c|c|c|}
\hline \multirow[b]{2}{*}{ Type of group } & Plaque score & e mean (SD) & \multirow{2}{*}{$\begin{array}{l}\text { Percentage of } \\
\text { decrease in the } \\
\text { plaque scores }\end{array}$} \\
\hline & Before training & After training & \\
\hline Reinforcers & $0.845(0.185)$ & $0.754(0.184)$ & 10.769 \\
\hline Nonreinforcers & $0.810(0.222)$ & $0.698(0.237)$ & 13.827 \\
\hline
\end{tabular}

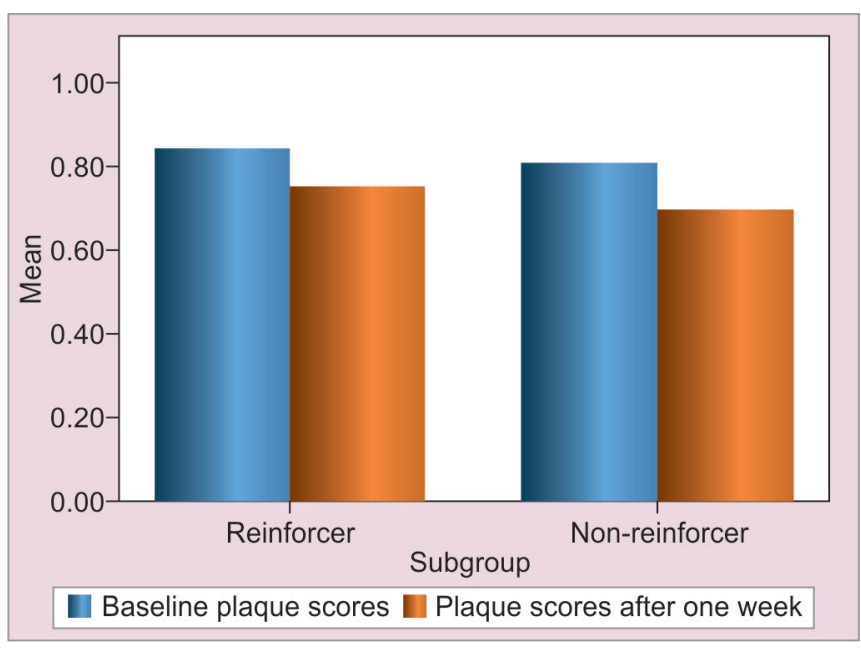

Graph 2: Average plaque scores at baseline and after training for the reinforcers and nonreinforcers group (including control group)

- $\mathrm{H}_{0 \mathrm{GTP}}$ : There was no significant interaction effect of groups, training methods, and pre- and posttraining sessions.

A two-way ANOVA with repeated measures was performed to test the above hypotheses. Repeated measures were used since the readings are taken for two timelines, baseline and after 1 week, i.e., pre- and posttraining session groups.

The analysis was carried out in two stages. The first stage consists of considering all the four groups (control group and three experimental groups), with the aim of testing whether there exists any significant difference in the plaque scores due to (i) different groups, i.e., methods of training; (ii) due to time line, i.e., pre- and posttraining; and (iii) interaction between groups and training methods. Repeated measures ANOVA was performed and the results are given in Table 3.

The results listed in Table 3 state that there is significant difference in the plaque scores due to (i) different groups, i.e., methods of training $(f=189.285, p=0.000)$;

Table 3: Results of the two-way repeated measures ANOVA

\begin{tabular}{lllll}
\hline & & & & Inference on the \\
Factor & $f$-value & $D F$ & $p$-value & null hypothesis \\
\hline Pre- and posttraining & 189.285 & 1 & 0.000 & Rejected \\
Training method & 7.717 & 3 & 0.000 & Rejected \\
Training method: & 8.122 & 3 & 0.000 & Rejected \\
*Pre- and posttraining & & & &
\end{tabular}

*Denotes significant difference among the scores 
Table 4: The pairwise difference among the four groups

\begin{tabular}{|c|c|c|c|c|}
\hline (I) Group & (J) Group & $\begin{array}{l}\text { Mean } \\
\text { difference } \\
(I-J)\end{array}$ & $\begin{array}{l}\text { Std. } \\
\text { error }\end{array}$ & Sig. \\
\hline \multirow[t]{3}{*}{ Control group } & $\begin{array}{l}\text { Individual instruction } \\
\text { on cast }\end{array}$ & $0.205^{*}$ & 0.060 & 0.006 \\
\hline & Audiovisual & 0.103 & 0.060 & 0.526 \\
\hline & Individual as model & -0.061 & 0.060 & 1.000 \\
\hline \multirow{3}{*}{$\begin{array}{l}\text { Individual } \\
\text { instruction on } \\
\text { cast }\end{array}$} & Control group & $-0.205^{\star}$ & 0.060 & 0.006 \\
\hline & Audiovisual & -0.102 & 0.060 & 0.545 \\
\hline & Individual as model & $-0.266^{*}$ & 0.060 & 0.000 \\
\hline \multirow[t]{3}{*}{ Audiovisual } & Control group & -0.103 & 0.060 & 0.526 \\
\hline & $\begin{array}{l}\text { Individual instruction } \\
\text { on cast }\end{array}$ & 0.102 & 0.060 & 0.545 \\
\hline & Individual as model & $-0.164^{*}$ & 0.060 & 0.045 \\
\hline \multirow{3}{*}{$\begin{array}{l}\text { Individual as } \\
\text { model }\end{array}$} & Control group & 0.061 & 0.060 & 1.000 \\
\hline & $\begin{array}{l}\text { Individual instruction } \\
\text { on cast }\end{array}$ & $0.266^{*}$ & 0.060 & 0.000 \\
\hline & Audiovisual & $0.164^{*}$ & 0.060 & 0.045 \\
\hline
\end{tabular}

*Denotes significant difference among the scores

(ii) due to time line, i.e., pre- and posttraining ( $\mathrm{f}=7.717$, $\mathrm{p}=0.000$ ); and (iii) interaction between groups and training methods $(\mathrm{f}=8.122, \mathrm{p}=0.000)$.

Table 4 indicates that control group is significantly different from individual instruction on cast, but not significantly different from audio visual group and individual as model. Individual instruction on cast is significantly different from individual as model but not significantly different from audio visual group. Audio visual group and individual as model are significantly different from each other.

Hence, we can conclude that the difference in the plaque scores are significant for different groups and are significantly different over different time lines, i.e., pre- and posttraining. Also, the training methods and time line interaction effect are also significant.

Though experimental groups are further divided into two subgroups namely, reinforcers and nonreinforcers for experimental groups, control group has only nonreinforcers. Hence, to study the effect of reinforcement of the training methods two-way repeated measures ANOVA was used only for experimental group and the following results are obtained.

The hypotheses tested in this study are concerned to experimental group only and the results are listed below:

- There was a significant difference in the plaque scores of different training methods ( $\mathrm{f}=12.218, \mathrm{p}<0.05)$.

- There was a significant difference in the plaque scores of two groups, reinforcers and nonreinforcers $(\mathrm{f}=4.897, \mathrm{p}<0.05)$.

- There was a significant difference in the plaque scores of subjects before and after training ( $\mathrm{f}=171.493$, $\mathrm{p}<0.05)$. Table 1 shows that there is a significant dip in the plaque scores due to training.
Table 5: Results of the two-way repeated measures ANOVA

\begin{tabular}{|c|c|c|c|c|}
\hline Factor & $F$-value & $D F$ & $p$-value & $\begin{array}{l}\text { Inference on the } \\
\text { null hypothesis }\end{array}$ \\
\hline Pre- and posttraining & 171.493 & 1 & 0.000 & Rejected \\
\hline Training method & 12.218 & 2 & 0.000 & Rejected \\
\hline Group & 4.897 & 1 & 0.031 & Rejected \\
\hline $\begin{array}{l}\text { Training method: *Pre } \\
\text { and posttraining }\end{array}$ & 7.022 & 2 & 0.022 & Rejected \\
\hline $\begin{array}{l}\text { Group: *Pre and } \\
\text { posttraining }\end{array}$ & 8.421 & 1 & 0.005 & Rejected \\
\hline $\begin{array}{l}\text { Training method: } \\
{ }^{*} \text { Group }\end{array}$ & 2.534 & 2 & 0.089 & Not rejected \\
\hline $\begin{array}{l}\text { Training method: } \\
{ }^{*} \text { Group: }{ }^{*} \text { Pre- and } \\
\text { posttraining }\end{array}$ & 0.153 & 2 & 0.859 & Not rejected \\
\hline
\end{tabular}

- There was a significant interaction effect due to training sessions and pre- and posttraining on plaque scores $(f=7.022, p<0.05)$, leading to the rejection of $\mathrm{H}_{\text {0тр. }}$.

- There was a significant interaction effect between reinforcing the training and pre- and posttraining on plaque scores $(f=8.421, p<0.05)$, leading to the rejection of $\mathrm{H}_{0 \mathrm{GP}}$

- There was no significant effect of the interaction of training methods, groups, and pre- and postgroups on the plaque scores $(f=0.153, p>0.05)$.

- There was no significant interaction effect of groups and training methods on the plaque scores $(\mathrm{f}=2.534$, $\mathrm{p}>0.05)$.

These results are tabulated in Table 5 .

Table 6 shows that there is a significant difference in the plaque scores for pre- and posttraining session groups.

Table 7 shows that the training method "individual as model" is significantly different from other two methods. From Table 1 we can see that the plaque scores for the third method of training is more compared with other two, for both pre- and posttraining sessions. Also, the percentage of dip in the plaque scores is minimum for this method.

A questionnaire consisting of five questions was administered on these 60 samples and the results were analyzed using simple descriptive statistics tools.

For the following three questions, all the three groups of training methods consisting of 20 units answered "yes." The questions are:

- Do you think your brushing is effective?

- Are you happy with the way you are brushing now?

- Has it helped you brush better?

The response of the sample units shows that the training was appreciated by them and they found it effective. For the question, "How many minutes do you brush now?", the first two groups answered as 2 to 3 minutes, 
Assessment of Efficacy of Different Teaching Methods of Tooth Brushing on Oral Hygiene Status in Adults

Table 6: Mean of the pre- and posttraining plaque scores of the reinforcer and nonreinforcer groups

\begin{tabular}{|c|c|c|c|c|c|}
\hline Group & Training method & Pre- or posttraining & Mean & $S D$ & Sig. \\
\hline \multirow[t]{6}{*}{ Reinforcer } & \multirow[t]{2}{*}{ Individual instruction on cast } & Preoperative & 0.7990 & 0.19284 & \multirow[t]{2}{*}{0.000} \\
\hline & & Postoperative & 0.6660 & 0.18179 & \\
\hline & \multirow[t]{2}{*}{ Audiovisual } & Preoperative & 0.7530 & 0.18019 & \multirow[t]{2}{*}{0.001} \\
\hline & & Postoperative & 0.6740 & 0.15714 & \\
\hline & \multirow[t]{2}{*}{ Individual as model } & Preoperative & 0.9830 & 0.09044 & \multirow[t]{2}{*}{0.001} \\
\hline & & Postoperative & 0.9210 & 0.06983 & \\
\hline \multirow[t]{6}{*}{ Nonreinforcer } & \multirow[t]{2}{*}{ Individual instruction on cast } & Preoperative & 0.6210 & 0.21068 & \multirow[t]{2}{*}{0.000} \\
\hline & & Postoperative & 0.4250 & 0.23066 & \\
\hline & \multirow[t]{2}{*}{ Audiovisual } & Preoperative & 0.8050 & 0.19512 & \multirow[t]{2}{*}{0.002} \\
\hline & & Postoperative & 0.6870 & 0.17802 & \\
\hline & \multirow[t]{2}{*}{ Individual as model } & Preoperative & 0.8930 & 0.18227 & \multirow[t]{2}{*}{0.001} \\
\hline & & Postoperative & 0.7770 & 0.16269 & \\
\hline
\end{tabular}

Table 7: Pairwise comparison of training methods

\begin{tabular}{lllll}
\hline $\begin{array}{l}\text { Training } \\
\text { method }(I)\end{array}$ & $(\mathrm{J})$ & $\begin{array}{l}\text { Mean } \\
\text { difference } \\
(I-J)\end{array}$ & $\begin{array}{l}\text { Std. } \\
\text { error }\end{array}$ & Sig. \\
\hline $\begin{array}{l}\text { Individual } \\
\text { instruction on } \\
\text { cast }\end{array}$ & $\begin{array}{l}\text { Audiovisual } \\
\text { Individual as model }\end{array}$ & $\begin{array}{l}-0.102 \\
-0.266^{*}\end{array}$ & 0.054 & 0.196 \\
Audiovisual & $\begin{array}{l}\text { Individual instruction } \\
\text { on cast }\end{array}$ & 0.102 & 0.000 \\
& $\begin{array}{l}\text { Individual as model } \\
\text { Individual }\end{array}$ & $-0.164^{*}$ & 0.054 & 0.196 \\
Individual as & $\begin{array}{l}\text { Individual } \\
\text { model }\end{array}$ & $\begin{array}{l}0.266^{*} \\
\text { instruction on cast }\end{array}$ & 0.054 & 0.000 \\
& Audiovisual & $0.164^{*}$ & 0.054 & 0.012 \\
\hline
\end{tabular}

*Denotes significant difference among the scores

whereas the third group's response was 3 minutes. When they were asked whether the new method of brushing was easy to learn, 15 out of 20 respondents (75\%) in the first group said, "Yes"; 12 out of $20(60 \%)$ in the second group said "yes"; and in the third group 16 out of $20(80 \%)$ found it easy. This shows that the respondents found the individual as model method simplest to follow, followed by the first method individual instruction on cast.

\section{DISCUSSION}

Mechanical plaque control can be effective, but needs to be meticulous and patients have to be highly motivated with an appropriate lifestyle (i.e., an appropriate diet, avoid smoking, etc.). Meticulous, self-performed plaque removal measures can modify both quantity and composition of subgingival plaque Dahlen et al. ${ }^{7}$

In the present study modified bass technique was the chosen brushing technique. Several clinical studies have reported modified bass technique as the effective technique of tooth brushing. Damle et al stated that modified bass technique is superior in cleaning the interproximal surfaces and gingival third of teeth than other techniques. ${ }^{8}$

The results in the present study have illustrated that there was a significant reduction in the plaque scores due to different training methods compared with control group. This indicates that by giving instructions through various methods, subjects were able to maintain their oral hygiene to some extent. The performance in brushing their teeth was improved by motivation obtained when the three methods of oral hygiene were applied. Daly et al reported that motivation, as demonstrated in this study, is one of the most important factors in ensuring optimal plaque control. ${ }^{9}$ In the experimental group, although all the methods showed reduction in the plaque scores, the maximum drop in the plaque scores was seen in group 2 (cast group). The result suggest that the subjects could understand the brushing technique better through the cast, which represents the oral cavity model and it was easier for the subjects to perceive the instructions in a better way.

Nearly similar methodology was followed by Srivastava et al. They reported similar results where reinforcement of the brushing techniques again after few days resulted in better reduction of plaque scores in children. ${ }^{2}$ Yet, in our study, it was found to be less effective. Although there was a significant difference in the plaque scores in the reinforcers and nonreinforcers, it did not influence the subjects in brushing better. It could be attributed to the age of the subjects, as they could understand the instructions well and reinforcement was not very essential.

A small survey was carried out among the participants using a questionnaire to assess the attitude toward the tooth brushing instructions during the follow-up period. The results indicated that all the subjects found the training session to be effective and the individual as model method to be simple to understand followed by individual instruction on cast.

Although brushing is a simple and effective way to remove dental plaque, the prevalence of periodontal disease in the general population shows that it is insufficient. ${ }^{10-12}$ Oral health education and training were effective in establishing good oral health habits among 
school children and also in enhancing the knowledge of their parents about good oral health. ${ }^{13,14}$ Stutcliffe et al concluded that oral hygiene instruction programs have potential value as a means of introducing young children to future dental procedures in a pleasant way as much possible. ${ }^{15}$ Similar results were reported in other studies, where direct communication with the dentist and chairside motivation for oral hygiene measures were effective motivational tools in improving the oral hygiene and gingival health status of children. ${ }^{16,17}$

\section{CONCLUSION}

The present study proves that there was significant reduction in the plaque scores due to different training methods compared with control group. Maximum reduction is seen in the individual instruction on cast method. There was significant difference in the plaque scores in the two groups, namely reinforcers and nonreinforcers. The pre- and postsession plaque scores are significantly different, showing that the training methods are effective in reducing the plaque scores.

\section{REFERENCES}

1. Patil SP, Patil PB, Kashetty MV. Effectiveness of different tooth brushing techniques on the removal of dental plaque in 6-8 year old children of Gulbarga. J Int Soc Prev Community Dent 2014 May;4(2):113-116.

2. Srivastava N, Vasishat A, Gupta G, Rana V. A comparative evaluation of efficacy of different teaching methods of tooth brushing in children contributors. J Oral Hyg Health 2013 Dec;1:118.

3. Axelsson P, Albandar JM, Rams TE. Prevention and control of periodontal diseases in developing and industrialized nations. Periodontology 2000 2002;29:235-246.

4. Lindhe J, Hamp S, Loe H. Plaque Induced periodontal disease in beagle dogs. A 4-year clinical, roentgenographical and histometrical study. J Periodontal Res 1975;10: 243-255.
5. Smulow JB, Turesky SS, Hill RG. The effect of supragingival plaque removal on anaerobic bacteria deep periodontal pockets. J Am Dent Assoc 1983 Nov;107(5):737-742.

6. Cancro LP, Fischman SL. The expected effect on oral health of dental plaque control through mechanical removal. Periodontology 20001995 Jun;8:60-74.

7. Dahlen G, Lindhe J, Sato K, Hanamura H, Okamoto H. The effect of supragingival plaque control on the subgingival microbiota in subjects with periodontal disease. J Clin Periodontol 1992 Nov;19(10):802-809.

8. Damle SG, Patil A, Jain S, Damle D, Chopla N. Effectiveness of supervised toothbrushing and oral health education in improving oral hygiene status and practices of urban and rural school children: a comparative study. J Int Soc Prev Community Dent 2014 Sep;4(3):175-181.

9. Daly CG, Chapple CC, Cameron AC. Effect of toothbrush wear on plaque control. J Clin Periodontol 1996 Jan;23(1):45-49.

10. Coonts EJ. Periodontics and oral hygiene. Quint Int 1983;7:739-742.

11. Kuhner M, Raetzke P. Relative effectiveness of various alternating frequencies of a power toothbrush. J Clin Periodontol 1993 Feb 20(2):75-80.

12. Almajed I. A comparative study between the double-headed toothbrush and the single headed toothbrush in plaque removal efficiency. J Clin Pediatr Dent 1994 Fall;19(1):19-21.

13. Martins CC, Oliveira MJ, Prodeus IA, Paiva SM. Comparison between observed children's toothbrushing habits and those reported by mothers. BMC Oral Health 2011 Sep;11:22.

14. Turska-Szybka A, Gozdowski D, Olczak-Kowalczyk D. Impact of individual health-oriented parent education on eating and hygiene habits, oral hygiene level and dentition condition in children with high risk of caries. Dev Period Med 2014;18(2):233-240.

15. Paunio P, Rautava P, Sillanpaa M, Kaleva O. Dental health habits of 3-year-old Finnish children. Community Dent Oral Epidemiol 1993 Feb;21(1):4-7.

16. Chanchra S, Dhawan P, Kaur T, Sharma AK. The most effective and essential way of improving the oral health status education. J Indian Soc Pedod Prev Dent 2011 Jul-Sep;29(3):216-221.

17. Acharya S, Goyal A, Utreja AK, Mohanty U. Effect of three different motivational techniques on oral hygiene and gingival health of patients undergoing multibracketed orthodontics. Angl Orthod 2011 May;81(5):884-888. 